\title{
Taking care of the caretaker: navigating compassion fatigue through a pandemic
}

\section{INTRODUCTION}

Clearly our world has changed. The World Health Organization (WHO) appointed 2020 'the Year of the Nurse and Midwife', however due to the impact of the pandemic on healthcare professionals (HCPs) internationally, the WHO extended the celebrations into 2021. Further, 'Nurses' Week' became 'Nurses' Month', and around the globe, people lauded the work of nurses and midwives. However, as we approach the fourth spike of COVID-19 in the United States, surging Delta-variant cases across the globe, and the second 'Year of the Nurse comes to an end', we wonder; "what's next?" Ask many nurses how they are doing, and there is a sense of uncertainty and hesitancy. Statistics show that approximately 32 percent of HCPs reported insomnia, while 40 percent exhibited anxiety symptoms. Similarly, more than 46 percent reported depression and 69 percent had high levels of stress. ${ }^{1}$ Considering these concerning reports, what impact has the pandemic made on the ability of HCPs to care for their suffering patients?

Both responding to the COVID-19 crises directly and carrying out routine care in the context of a pandemic is extremely taxing on an often already stretched workforce. Nurses and midwives are complaining of extreme exhaustion, emotional distress, and physical anguish from long hours of wearing face masks and other personal protective equipment. ${ }^{2-3}$ In addition, they fear transmitting the coronavirus disease from the workplace to their family members, which causes some to live away from home. ${ }^{2}$ Even more distressing for many is the thought of providing high quality patient care, while accommodating for the surge of patients with viral infections, caring for colleagues with COVID-19, and treating patients without family at their side. ${ }^{2}$ The reality is that many nurses find themselves as the only person at the patient's bedside due to visitor restrictions. This leaves HCPs both overworked and vulnerable to bearing the weight of their own and other's suffering. This has exposed HCPs to predisposing risks of compassion fatigue (CF). ${ }^{4}$

\section{WHAT IS COMPASSION FATIGUE?}

Compassion fatigue is the gradual physical and emotional withdrawal experienced by those who take care of traumatised and sick patients. ${ }^{5}$ Specifically, CF is the intersection of burnout (the response to things at work such as under staffing or bullying caused by excessive and prolonged stress), vicarious trauma (suffering caused by seeing others suffer), and primary traumatic stress (the impact of personal daily stressors, including previous traumas, such as adverse childhood experiences). ${ }^{6-7}$ It is an extreme state of tension and preoccupation with the suffering of those being helped to the degree that it can create a secondary traumatic stress for the HCP. ${ }^{6}$

It is estimated that $48-53$ percent of nurses experience compassion fatigue, which could be understood as the impact or cost of caring. ${ }^{8}$ Nurses are known for their ability to alleviate patient suffering, however, lack of effective resources and knowledge of how to effectively treat patients with COVID-19 has left many HCPs feeling powerless to care for the sick and suffering in their care. Evidence suggest that HCPs can experience various negative emotions such as distress and extreme sadness when working in high stress and high-risk environments such as during a disaster or pandemic. ${ }^{9}$

\section{MANIFESTATIONS OF COMPASSION FATIGUE}

Compassion fatigue can have negative consequences in multiple areas of HCP's professional and personal life and include aspects of burnout. These consequences can be physical, behavioural, psychological-emotional, and spiritual (see Figure 1$).{ }^{10}$

Compassion fatigue can affect people differently. It may be experienced as reduced job satisfaction or engagement or as decline in physical or mental health. People affected by CF may suffer from feelings of hopelessness, exhaustion, or be less willing to spend time with patients. ${ }^{4}$ There is a longlasting effect on HCPs that witness prolonged suffering of patients lasting anywhere from months to years. ${ }^{3}$ 

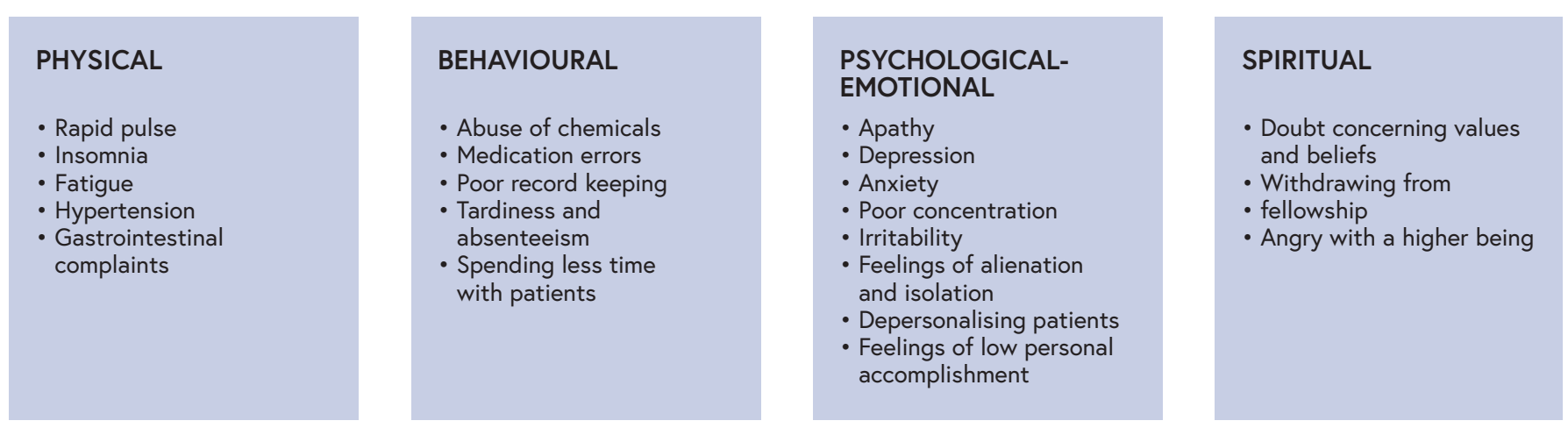

FIGURE 1: CATEGORICAL MANIFESTATIONS OF COMPASSION FATIGUE ${ }^{10}$

\section{ADDRESSING COMPASSION FATIGUE}

There are known protective factors against and strategies to reduce CF and other emotional stresses including; socialising, mindfulness habits, healthy lifestyle habits, journaling, and seeking professional help. These protective factors focus on resiliency, self-efficacy, and perceived support (see Figure 2). ${ }^{11}$

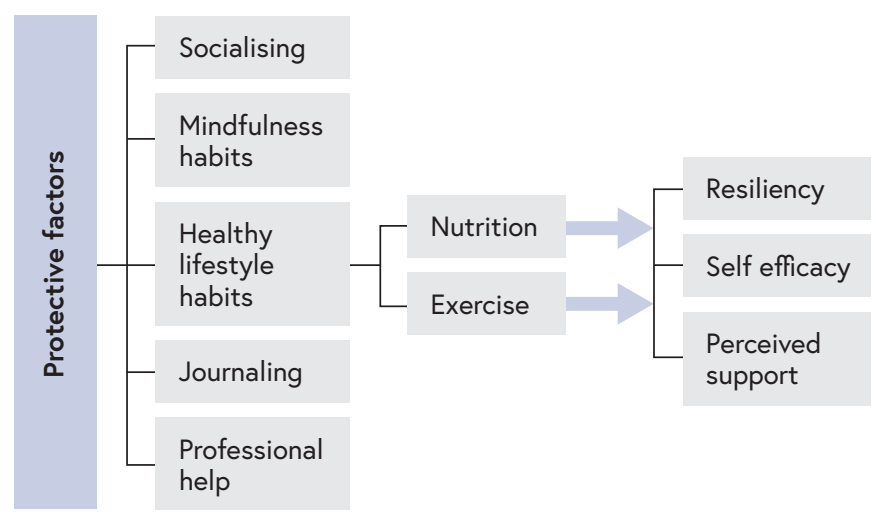

FIGURE 2: PROTECTIVE FACTORS AGAINST COMPASSION FATIGUE ${ }^{11}$

The management of CF must be multi-dimensional and include prevention, assessment, and consequence minimisation. ${ }^{11}$ The nursing profession has to be bold and acknowledge that compassion fatigue is a critical risk within many healthcare environments and is amplified by the pandemic situation in many contexts. The WHO recognises HCP's reactions to emotional stress due to their work environment as an occupational health and safety hazard, but CF is not well recognised as a barrier to providing quality care. If CF is not addressed early, it can alter the ability of HCPs to provide compassionate care and negatively impact their own health, safety, and wellbeing. Experiences of CF may also be linked with poorer workforce retention. Currently, there are few support strategies and interventions in healthcare organisations to assist nurses in dealing with sadness, grief, and loss. ${ }^{11}$ While it is important for HCPs to take ownership of their mental health and wellbeing, employers of HCPs should also take responsibility for their workers. ${ }^{3}$ Organisational consequences of CF can include reduced patient safety outcomes, negative workforce impacts, and greater costs. ${ }^{12}$

A more proactive approach to the development of strategies that address the mental health and well-being of HCPs could provide solutions for preventing and reducing CF among HCPs. Interventions that focus on work/life balance, education, and strategic interventions within the work environment have been shown to be beneficial. ${ }^{11}$

We believe there should be intentionality in nurturing self, in order to nurture others. This balance involves creating a self-care routine to attempt to enhance one's own well-being. This is a way to render compassionate care for self. Some ways to render compassionate care include exercising, journaling, meditating, mindfulness, and doing things that focus on pleasurable, non-working related activities. ${ }^{11}$ Unfortunately, the pandemic has made opportunities to engage in some of these activities harder. Creating the time for self, even throughout a busy shift, will be requisite for mitigating the impact of collateral damage in this historically, and globally stressful time in healthcare.

Lack of knowledge on CF risk factors often leads to a lack of communication skills for effective coping when under stress. ${ }^{11}$ Strategies for communicating in stressful situations could improve nurses and midwives' ability to identify personal coping strategies, develop caring communication styles, and establish boundaries with colleagues and patients. In addition, education can assist HCPs to utilise self-care strategies such as mediation and mindfulness and coping with ethical conflict and dilemmas. ${ }^{11}$

Workplace interventions are imperative to address the emotional distress nurses and midwives are currently experiencing. ${ }^{11,12}$ Workplaces that offer a multitude of resources to assist healthcare providers with their mental health and wellbeing are considered 'healthy work environments'. Resources such as on-site counseling, support groups for staff, art therapy, massage sessions, bereavement interventions, and de-briefing sessions are beneficial in supporting healthcare providers in alleviating CF and emotional distress (see Figure 3$){ }^{11}$ While some of these resources would be hard to implement in the midst of a 
pandemic, future planning could embed these opportunities within the strategic goals of organisations so resources are available for HCPs during future crises. Workplace leaders should develop programs that assist in developing resilience, assessment of mental health and wellbeing, and interventions that assist in minimising the consequence of extreme workplace stressors during a pandemic.

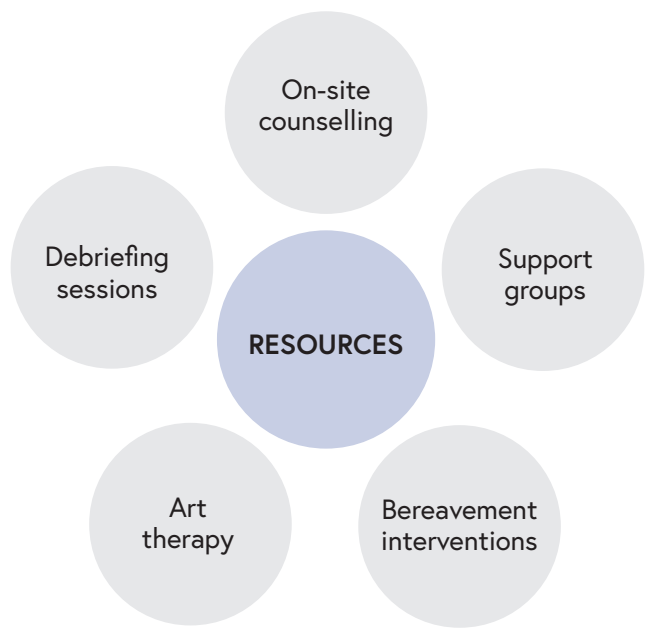

FIGURE 3: HEALTHY WORKPLACE STRATEGIES TO IMPROVE THE MENTAL HEALTH AND WELLBEING OF HCPS ${ }^{11}$

\section{CONCLUSION}

In a caring profession, often nurses neglect their own needs to care for their patients. I can recall the impact of the 2005 Hurricane Katrina among Louisiana nurses, and the toll it had on their mental health. It was devastating. Nurses were exposed to the various socioeconomic inequalities, the racism, and the lack of access to healthcare that many of their patients also experienced. Nurses had to watch the suffering of their patients for several days without adequate resources. To this day, you can hear stories about the trauma that they are still addressing. It is essential that nurses learn the skills that will be a requisite for their survival. There must be an integration of self-care and mental health and wellness behaviours into our daily routine. To date, over four million people have died from the COVID-19 virus worldwide, ${ }^{13}$ and approximately 700 thousand in the United States. ${ }^{14}$ The impact of the pandemic has been traumatising for many nurses and midwives. A collaborative effort between hospital administrators and HCPs is imperative in assessing, implementing, and mitigating compassion fatigue that is a normal response to the abnormal exposure to trauma in this critical frontline workforce.

\section{Benita N Chatmon PhD, MSN, RN, CNE}

School of Nursing, LSU Health New Orleans, New Orleans, LA, USA

\section{Ecoee Rooney DNP, RN, NPD-BC, SANE-A}

System Nursing Professional Development, Ochsner Health, New Orleans, LA, USA

\section{REFERENCES}

1. Chen R, Sun C, Chen J, Jen H, Kang XL, Kao C, et al. A LargeScale Survey on Trauma, Burnout, and Posttraumatic Growth among Nurses during the COVID-19 Pandemic. International Journal of Mental Health Nursing [Internet]. 2021 Feb [cited 2021 Aug 4];30(1):102-16. Available from: http://search ebscohost.com/login. aspx?direct=true \&db=ccm\&AN=14838385 9\&site=eds-live\&scope=site

2. Miotto K, Sanford J, Brymer MJ, Bursch B, Pynoos RS. Implementing an emotional support and mental health response plan for healthcare workers during the COVID-19 pandemic. Psychological Trauma: Theory, Research, Practice, and Policy [Internet]. 2020 Aug [cited 2021 Aug 4];12(S1):S165-7. Available from: http://search.ebscohost.com/login. aspx?direct $=$ true \&db=pdh\&AN=2020-41742-001\&site=edslive\&scope $=$ site

3. Arnetz JE, Goetz CM, Arnetz BB, Arble E. Nurse Reports of Stressful Situations during the COVID-19 Pandemic: Qualitative Analysis of Survey Responses. International Journal of Environmental Research and Public Health [Internet]. 2020 Nov 1 [cited 2021 Aug 4];17(21). Available from: http://search. ebscohost.com/login.aspx?direct=true \&db=edswss\&AN=0005 $88919400001 \&$ site $=$ eds-live \&scope $=$ site

4. Perregrini, M. Combating compassion fatigue. Nursing2019 [Internet]. 2019 Feb [cited 2021 Aug 8];49(2):50-54. Available from: http://search.ebscohost.com.ezproxy.lsuhsc.edu/

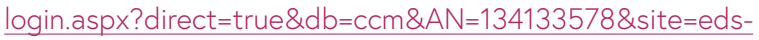
live\&scope=site

5. Peters E. Compassion fatigue in nursing: A concept analysis. Nursing forum [Internet]. 2018 Oct [cited 2021 Aug 8];53(4):466-80. Available from: http://search.ebscohost.com/ login. asp $x$ ?direct $=$ true \& db=cmedm\&AN=29962010\&site=edslive\&scope=site

6. Figley CR. Compassion Fatigue: Coping with Secondary Traumatic Stress Disorder in Those Who Treat the Traumatized. Compassion Fatigue: Coping with Secondary Traumatic Stress Disorder in Those Who Treat the Traumatized [Internet]. 1995 [cited 2021 Aug 5]; Available from: http://search.ebscohost. com.ezproxy.lsuhsc.edu/login. aspx? direct=true $\& d b=\operatorname{sih} \& A N=S$ M156237\&site=eds-live\&scope=site

7. Maslach, C. (1982). Burnout — The cost of caring. Englewood Cliffs, New Jersey: Spectrum.

8. Zhang Y-Y, Han W-L, Qin W, Yin H-X, Zhang C-F, Kong C, et al. Extent of compassion satisfaction, compassion fatigue and burnout in nursing: A meta-analysis. Journal of nursing management [Internet]. 2018 Oct [cited 2021 Aug 5];26(7):8109. Available from: http://search.ebscohost.com/login.aspx?dire $c t=$ true \& db=cmedm\&AN=30129106\&site=eds-live\&scope=site

9. Alharbi J, Jackson D, Usher K. The potential for COVID-19 to contribute to compassion fatigue in critical care nurses. Journal of clinical nursing [Internet]. 2020 Aug [cited $2021 \mathrm{Jul}$ 27];29(15-16):2762-4. Available from: http://search.ebscohost. $\mathrm{com} /$ login.aspx?direct=true $\& \mathrm{db}=\mathrm{cmedm} \& A N=32344460 \&$ site $=$ eds-live\&scope $=$ site

10. Aycock N, Boyle D. Interventions to manage compassion fatigue in oncology nursing. Clinical Journal of Oncology Nursing [Internet]. 2009 Apr [cited 2021 Jul 27];13(2):183-91. Available from: http://search.ebscohost.com.ezproxy.lsuhsc. edu/login aspx? direct=true \&db=ccm\&AN=105501094\&site $=e$ ds-live\&scope=site 
11. Boyle DA. Countering Compassion Fatigue: A Requisite Nursing Agenda. Online Journal of Issues in Nursing [Internet]. 2011 Jan [cited 2021 Jul 27];16(1):1. Available from: http://search. ebscohost.com.ezproxy.lsuhsc.edu/login.aspx?direct=true\&db= ccm\&AN=104894928\&site=eds-live\&scope $=$ site

12. Kelly L. Burnout, Compassion Fatigue, and Secondary Trauma in Nurses: Recognizing the Occupational Phenomenon and Personal Consequences of Caregiving. Critical care nursing quarterly [Internet]. 2020 Jan [cited 2021 Aug 8];43(1):73-80. Available from: http://search.ebscohost.com/login.aspx?direct= true\&db=cmedm\&AN=31789880\&site=eds-live\&scope=site

13. National Health Commission (NHC) of the People's Republic of China. Coronavirus Death Toll. [place unknown], [publisher unknown] 2021 [updated 2021; cited 2021 Aug 8]. Available from: https://www.worldometers.info/coronavirus/coronavirusdeath-toll/

14. National Center for Health Statistics. COVID-19 Mortality Overview. [place unknown], [publisher unknown] 2021 [updated 2021; cited 2021 Aug 8]. Available from: https://www.cdc.gov/ nchs/covid19/mortality-overview.htm 